\title{
Desregulamentação dos Mercados de Trabalho e Desemprego nas Economias Capitalistas Avançadas
}

\author{
Deregulation of Labor and Unemployment \\ Markets in Advanced Capitalist Economies
}

LUIZ ANTÔNIO DE OLIVEIRA LIMA*

\begin{abstract}
RESUMO: O objetivo desta pesquisa é discutir a relevância de fatores micro e macroeconômicos como determinantes do atual nível de desemprego em algumas economias capitalistas avançadas. Através desses resultados, será possível determinar a importância da hipótese convencional de que altos níveis de desemprego podem ser explicados pela rigidez do mercado de trabalho e por suas implicações políticas.

PALAVRAS-CHAVE: Desemprego; desregulamentação; rigidez de salários.

ABSTRACT: The aim of this research is to discuss the relevance of micro and macroeconomic factors as the determinants of the present level of unemployment in some advanced capitalist economies. Through these results it will be possible to determine the importance of the conventional hypothesis that high levels of unemployment can be explained by the rigidities in the labor market as well as its policy implications.

KEYWORDS: Unemployment; deregulation; wage rigidity.

JEL Classification: J65; J81; J31.
\end{abstract}

\section{INTRODUÇÃO}

A visão ortodoxa do problema do desemprego tem colocado as seguintes alternativas para os assalariados: ou aceitar a precarização das ocupações e redução salarial (modelo americano) ou conviver com altas taxas de desemprego (modelo europeu). $\mathrm{Na}$ verdade, a primeira alternativa retoma os pressupostos clássicos da teoria do emprego, criticados por Keynes nos anos 30, quando apontou como causa do desemprego, não as condições do mercado de trabalho, mas sim as condições da criação da renda e a condução das políticas macroeconômicas.

As altas taxas de desemprego na Europa, combinadas com um relativo suces-

\footnotetext{
* Professor do Departamento de Economia da Fundação Getúlio Vargas, São Paulo/SP, Brasil. E-mail: laolima40@gmail.com.
} 
so dos Estados Unidos em manter taxas reduzidas, desde o início dos anos 70, como mostra a Tabela 1, têm servido para reforçar a proposta ortodoxa para tratar o problema. Assim a revista The Economist, tomando como base tal tipo de informação, aponta taxas reduzidas de desemprego para países que desregulamentaram e flexibilizaram seus mercados de trabalho, como Estados Unidos, Inglaterra; e taxas elevadas para países com mercados regulamentados, como França, Alemanha, Itália, Suécia. Com base nessa constatação, observa-se que "se a regulamentação do mercado de fato protegesse o emprego, a performance europeia em termos de emprego seria melhor e não pior que a americana. A evidência é clara: a forma de se cortar o desemprego é desregulamentar, "afinar" o welfare state e cortar os salários, especialmente os custos não-salariais; e não o que os europeus têm feito, regulamentar, proteger o welfare e permitir que os custos nãosalariais atinjam o teto. Tais fatos apontam para o problema crucial. A chegada de uma moeda única torna mais urgente a realização de amplas reformas estruturais para as economias esclerosadas da Europa". (The Economist, abril de 1998. EMU Survey, p. 7).

Tabela 1: Taxas de Desemprego, em alguns países da OECD 1973 - 1996

\begin{tabular}{lcccc}
\hline Países & 1973 & 1979 & 1989 & 1996 \\
\hline França & 2,7 & 5,9 & 9,4 & 12,3 \\
Alemanha & 0,8 & 3,2 & 5,5 & 9,0 \\
Itália & 6,2 & 7,6 & 10,9 & 11,9 \\
Reino Unido & 3,0 & 5,0 & 7,2 & 8,2 \\
EUA & 4,8 & 5,8 & 5,2 & 5,4 \\
\hline
\end{tabular}

Fontes : OECD Employment Outlook, U.S. Bureau of Labour Statistics.

Tal análise no entanto requer uma reflexão crítica mais ampla, principalmente se considerarmos que trabalhos empíricos desenvolvidos por economistas de tendências variadas contestam muitos dos pontos acima apresentados. Assim, Buchelle e Christiansen (1998) questionam "a implicação que a Europa deveria adotar o estilo americano de desregulamentação e de flexibilidade dos mercados de trabalho. Um exame detalhado dos dados dos EUA e dos E-4 (França, Alemanha, Itália e Reino Unido) não revela qualquer diferença para homens na faixa etária de 24 a 54 anos (prime age males), mas sim diferenças elevadas para outros grupos demográficos, tanto considerando-se um país isolado como todos os países (e não apenas os EUA e os E-4). Também consideramos o impacto de várias regulamentações do emprego, regulamentação de salários, e políticas de garantia de renda no desemprego. Concluímos pela não-evidência de efeitos negativos, e de maneira mais importante, que as mesmas instituições que podem elevar o desemprego na Europa estão contribuindo para o crescimento mais rápido dos salários e maior igualdade em relação aos EUA” (p. 117).

Stephen Nickel observa que, embora certos traços do mercado possam ser considerados como formas de rigidez, (existem) muitos deles que não causam desemprego elevado e de fato podem servir para propósitos positivos. Assim é impor- 
tante determinar-se quais dessas características dos mercados de trabalho podem causar desemprego elevado e quais não causam" (Nickel, 1997, p. 55).

De maneira mais categórica, Gregg e Manning (1997) ressaltam "que a relação entre a regulamentação do mercado de trabalho e desemprego é mais complexa do que é geralmente sugerido e que existem instâncias em que a desregulamentação intensa leva de fato a um maior desemprego ou a outras formas de ineficiência na operação desse mercado" (p. 396).

Tais considerações justificam uma análise capaz de identificar, de maneira objetiva, os determinantes do desemprego nos países capitalistas mediante uma discussão de suas causas micro e macroeconômicas. Tendo em vista atingir esses objetivos, se procurará discutir os seguintes tópicos, para as principais economias europeias e a americana:

- uma avaliação geral da flexibilidade dos seus mercados de trabalho;

- as formas de regulamentação dos mercados, e o efeito dessas formas de regulamentação sobre o emprego e o desemprego;

- um modelo de interpretação macroeconômica do desemprego;

- os efeitos das políticas macroeconômicas recentes como possível explicação das diferenciais de desemprego nessas economias.

\section{UMA AVALIAÇÃO GLOBAL DA FLEXIBILIDADE DOS MERCADOS DE TRABALHO EUROPEU E AMERICANO}

O passo inicial de uma análise dos mercados de trabalho é a consideração de seu grau de atividade ou de seu dinamismo. Tal consideração permitirá identificar se realmente os mercados de trabalho da Europa são esclerosados, dando lugar à chamada "euroesclerose", em oposição ao mercado americano normalmente considerado "dinâmico".

Um dos critérios para identificar tais situações será o de se considerar as taxas de criação e destruição de empregos. Dados referentes a algumas economias europeias e à americana estão apresentadas na tabela a seguir.

A Tabela 2 mostra que, para fases iguais do ciclo, Dinamarca, França e Suécia, países com mercados mais regulados e com programas de welfare mais amplos que o americano, tiveram taxas maiores de criação de emprego que os EUA. De outro lado, se os EUA produziram mais emprego que a França, Dinamarca e Suécia através da abertura de novas firmas, estes países, bem como Itália, Alemanha, Finlândia e Reino Unido, produziram mais emprego que os EUA mediante a expansão das firmas já existentes. 
Tabela 2: Criação e destruição de emprego nos EUA e alguns países da União Européia (EU) (taxas médias anuais como \% do emprego)

\begin{tabular}{|c|c|c|c|c|c|c|c|c|}
\hline & $\begin{array}{c}\text { Dinamarca } \\
\text { 1983-89 }\end{array}$ & $\begin{array}{c}\text { Finlândia } \\
\text { 1986-91 }\end{array}$ & $\begin{array}{c}\text { França } \\
\text { 1986-97 }\end{array}$ & $\begin{array}{c}\text { Alemanha } \\
\text { 1983-90 }\end{array}$ & $\begin{array}{c}\text { Itália } \\
\text { 1984-92 }\end{array}$ & $\begin{array}{l}\text { Suécia } \\
1985-92\end{array}$ & $\begin{array}{c}\text { Reino Unido } \\
\text { 1985-92 }\end{array}$ & $\begin{array}{c}\text { EUA } \\
1984-91\end{array}$ \\
\hline $\begin{array}{l}\text { Criação de } \\
\text { empregos }\end{array}$ & 16,0 & 10,4 & 13,9 & 9,0 & 12,4 & 14,5 & 8,7 & 13,0 \\
\hline Novas firmas & 6,1 & 3,9 & 7,2 & 2,5 & 3,9 & 6,5 & 2,7 & 8,4 \\
\hline Expansão & 9,9 & 6,5 & 6,7 & 6,5 & 8,4 & 8,0 & 6,0 & 4,6 \\
\hline $\begin{array}{l}\text { Perda de } \\
\text { empregos }\end{array}$ & 13,8 & 12,0 & 13,2 & 7,5 & 11,1 & 14,6 & 6,6 & 10,4 \\
\hline $\begin{array}{l}\text { Fechamento } \\
\text { de firmas }\end{array}$ & 50 & 3,4 & 7,0 & 1,9 & 3,8 & 5,0 & 3,9 & 7,3 \\
\hline Contratação & 8,8 & 8,7 & 6,3 & 5,6 & 7,3 & 9,6 & 2,7 & 3,1 \\
\hline $\begin{array}{l}\text { Variação } \\
\text { líquida }\end{array}$ & 2,2 & $-1,6$ & 0,6 & 1,5 & 1,3 & $-0,1$ & 2,1 & 2,6 \\
\hline Turn-over & 29,8 & 22,4 & 27,1 & 16,5 & 23.4 & 29,1 & 15,3 & 23,4 \\
\hline
\end{tabular}

Fonte: OECD - Job Study: Investment Productivity and Employment (Paris, 1995).

Explica-se por que esses países tiveram uma taxa líquida de criação de empregos inferior à americana: suas taxas de destruição de emprego foram maiores (exceto Alemanha e Reino Unido), o que se deveu mais ao fato de as firmas reduzirem o emprego do que ao seu fechamento. De outro lado, se considerarmos o turnover, um índice importante de flexibilidade de mercado, com exceção da Alemanha e Reino Unido, veremos que os países europeus tiveram turnover maior que o americano (Navarro, 1998, p. 68). Qual a conclusão que se pode tirar desses dados? Se a explicação convencional de que a maior perda de empregos dos países europeus é devida à rigidez de mercado, como se explicaria a maior taxa de criação de empregos que dos EUA para os países mais regulados da Europa: Suécia, Dinamarca e França? Não se pode ter as duas coisas simultaneamente, isto é, as taxas de criação de emprego também deveriam ser maiores para a economia americana.

Outro argumento importante da "sabedoria convencional” é a de que as taxas mais elevadas de desemprego dos países europeus decorrem de os salários serem mais altos na União Européia devido a sua rigidez para baixo. Ora, de acordo com tal argumento, qualquer tendência dos salários superarem a taxa de crescimento da produtividade se refletiria no aumento da participação dos salários no valor do produto da economia, o que implicaria, então, uma depressão do nível de lucros. Tal comportamento dos salários não é o que mostram os dados apresentados na Tabela 3. 
Tabela 3: Participação do Salário no PIB a custo de fatores

\begin{tabular}{lccccccccccc}
\hline & $1971-80$ & 1981 & 1985 & 1990 & 1991 & 1992 & 1993 & 1994 & 1995 & 1996 & 1997 \\
\hline $\begin{array}{l}\text { União } \\
\text { Européia }\end{array}$ & 75.4 & 76,7 & 73,0 & 70,7 & 70,9 & 71,0 & 70,8 & 69,5 & 68,8 & 68,7 & 68.4 \\
\hline $\begin{array}{l}\text { Estados } \\
\text { Unidos }\end{array}$ & 72,1 & 71,7 & 71,0 & 71,8 & 72,6 & 72,4 & 72,0 & 72,1 & 71,9 & 71,3 & 72,4 \\
\hline
\end{tabular}

Fonte : European Economy (1995, 1996, 1997), transcrito em Pelagidis 11998).

Os dados acima, contrariamente à ideia de uma elevação da participação dos salários na economia europeia, indicam que a parte dos salários reduziu-se continuamente desde o início dos anos 80, de 76,7\% em 1981 para 68,4\% em 1997, ao passo que permaneceu estável para a economia americana no período 81-87.

Sobre esse ponto, observa Pelagidis (1998):

“A elevação média dos salários reais na Europa entre 1992 e 1996 foi de cerca de $0,7 \%$, enquanto o correspondente crescimento da produtividade no mesmo período foi de $2 \%$ (Eurostat \& DGII 1996). Se acrescentarmos a isto a redução da participação dos salários na renda, então somos claramente levados à conclusão de que o comportamento dos salários reais não caracteriza inflexibilidade no mercado de trabalho e não é responsável pelo aumento do desemprego e da pobreza na Europa” (p. 80).

\section{DESEMPREGO E REGULAMENTAÇÃO DOS MERCADOS DE TRABALHO}

$\mathrm{Na}$ análise abaixo se considerará o efeito de três espécies de instituições de mercado, que em princípio tornariam rígidos os mercados de trabalho e explicariam taxas elevadas de desemprego: a) leis de proteção ao emprego; b) padrões de regulamentação salarial; c) seguro desemprego e outras formas de rendimentos garantidos.

\section{Leis de proteção ao emprego}

Tal tipo de proteção tem um efeito que pode ser considerado ambíguo; ao mesmo tempo que pode reduzir o processo de demissões, de outro pode também reduzir a tendência à contratação, na medida em que o empresário pode antecipar dificuldades na redução de sua força de trabalho no futuro. O problema então é o de se tentar estabelecer qual dessas duas tendências terá maior importância.

De acordo com a análise apresentada por Buchelle e Christiansen (op. cit., pp. 123-6), dos E-4, o Reino Unido é o país que apresenta uma maior consistência no processo de desregulamentação, ao passo que para Alemanha, Itália e França tem havido uma tendência a se manter ativa tal proteção. Em relação aos EUA, sabemos que a proteção ao emprego pode ser descrita pela expressão employment at will, isto é, os empregados podem ser demitidos sem aviso prévio ou qualquer tipo de 
compensação. Para esses autores, a verificação empírica dos efeitos acima mencionados não revela tendências muito claras. Assim é que o OECD Job Study admite que diferentes relações emprego/população estão correlacionadas negativamente com os índices de proteção, embora admita de outro lado que a desregulamentação pode simultaneamente estimular a criação de postos de trabalho como também criar riscos de desemprego em situações em que predominam ou predominavam contratos de trabalho a termo.

Nickel (1997), por sua vez, procurou através de uma regressão simples explicar o efeito da proteção sobre o emprego, estabelecendo um "ranking" do grau de proteção para diferentes países da OECD, de acordo com um índice de proteção estabelecido pela própria OECD. Tais países foram classificados de 1 a 20, com os de peso 20 sendo os mais regulados. Em tal análise, baseada em duas "cross sections"

de 1983-88 e 1989-1994, em que as variáveis dependentes são desemprego total, desemprego de longo prazo e desemprego de curto prazo, se obteve coeficientes de regressão negativos para o desemprego total e o desemprego de curto prazo, respectivamente $-0,0032$ e - 0,046 . Esse resultado indica que o efeito global (da proteção) "tende a ser muito pequeno à medida que os seus efeitos tendem a se cancelar. Tais resultados confirmam a análise de Bentolila e Bertola (1990)" (Nickel, 1997, p. 66).

\section{Padrões de regulamentação salarial}

Dentre as formas de regulamentação salarial, inclui-se: sindicalização; negociação coletiva e salário mínimo. Tradicionalmente supõe-se que inibem ou reduzem a flexibilidade para baixo dos salários e assim reduzem o emprego. Consideremos cada uma dessas formas de regulamentação para verificar ou não tal hipótese. Sindicalização e Regulamentação - Supõe-se que inibem ou reduzem a flexibilidade em função de darem ao assalariado um maior poder de barganha. Se considerarmos a experiência de sindicalização, vamos verificar que para França, Alemanha e Itália, considerando-se o período dos anos 60 aos 90, até o início dos anos 80 , houve uma clara tendência para seu aumento, sendo que a partir dos anos 80 começou a cair (OECD Employment Outlook, 1991 e 1994). Em relação aos acordos coletivos segundo essa mesma fonte, a variação tem sido muito assistemátic para esses países para se estabelecer uma tendência.

A avaliação empírica do efeito dessas variáveis tem apresentado resultados algumas vezes contraditórios. Nickel (1997), na análise anteriormente mencionada, obteve coeficiente de regressão positiva entre um índice de intensidade de sindicalização (variando de 1 a 3) e o desemprego total, e o desemprego a curto e longo prazo. Porém, Gregg e Manning (1996) através de uma análise de "cross section" de dados de 16 países da OECD, correspondentes ao ano de 1990, verificaram uma correlação negativa entre a densidade sindical e o nível de desemprego (p. 406).

Salário Mínimo - Considerando-se os países do E-4 e os Estados Unidos verificamos que há três diferentes métodos de determinação do salário mínimo. Há um mínimo legal para a França e EUA; há dissídios coletivos para diferentes seto- 
res da economia, estabelecendo diferentes níveis para cada setor, para Alemanha e Itália, enquanto para o Reino Unido havia um mínimo estabelecido apenas para os setores de baixos salários, o que no entanto foi abolido.

Sobre o efeito do salário mínimo sobre o desemprego, há evidência de que "o salário mínimo não esteja atualmente associado a uma pobre performance do mercado de trabalho. Isto é consistente com recente análise empírica microeconômica para os Estados Unidos e Reino Unido. Estudos para os EUA, realizados por Card (1992 a 1992b), Carde Krueger (1994) e Katz Krueger (1992) e estudos para o Reino Unido por Machin e Manning (1994a) e Orckens et al. (1994), encontraram efeito nulo ou positivo do salário mínimo sobre o emprego" (Gregg e Manning, 1997, p. 409). Tais resultados são consistentes com a observação de Nickel, de que "o salário mínimo tende a ser muito baixo para ter um efeito importante sobre o emprego masculino adulto. De outro lado, o salário mínimo pode ter um impacto significativo, embora pequeno, na taxa de desemprego dos jovens, especialmente em países como Espanha e França onde os tributos na folha salarial são elevados e onde pouco se fez para um ajustamento do salário mínimo às diferentes faixas de idade" (Nickel, 1997, p. 70).

\section{Seguro desemprego e renda garantida}

Supõe-se que essas características do mercado de trabalho estão associadas por dois motivos: diretamente, ao elevar o salário de reserva do trabalhador, podem prolongar o período de procura de trabalho e, portanto, a disponibilidade ao desemprego; indiretamente, ao reduzir "o custo do desemprego", aumenta o poder de barganha do assalariado, e portanto, aumenta o salário de reserva e o desemprego voluntário; dando origem à chamada "armadilha do desemprego".

A quantificação desses benefícios aos desempregados pode ser feita mediante dois critérios: duração do benefício e alcance (percentual dos desempregados recebendo benefício). Uma apresentação desses valores para os países dos E-4 e Estados Unidos foi sistematizado por Blondal e Pearson (1995), a partir de um índice de benefícios que é a média simples do replacement rate (renda recebida nos primeiros meses de desemprego como uma percentagem da renda de um desempregado), em três circunstâncias (solteiro, com esposa dependente e com esposa empregada) por três durações ( 3 anos, 4 anos e 5 anos), e por dois níveis de rendimento (médio e dois terços do rendimento médio).

Supondo-se que tais índices de benefício devam estar associados diretamente com as taxas de desemprego de longo prazo (desemprego por 1 ano ou mais), Buchelle e Christiansen (1998, pp. 132-3) compararam os rankings de tais índices com o ranking das taxas de desemprego de longo prazo para os países acima considerados. Tal comparação para 1993 mostrou que os países mais generosos em termos de benefícios são aqueles que apresentam menores taxas de desemprego de longo prazo, ajustadas para encarceramento e desencorajamento. De outro lado, Itália e Reino Unido, os que apresentam menores índices de benefícios, são aquele que apresentam maiores taxas de desemprego de longo prazo. Se considerarmos os 
índices não ajustados, a falta de correlação se repete; desde que deixemos de lado EUA, teremos Alemanha e França com os maiores índices de benefícios e taxas de desemprego mais baixas.

Estatisticamente, não é simples comprovar o efeito dos benefícios sobre a taxa de desemprego, por várias razões:

a) os países tendem a aumentar os benefícios pelo desemprego quando a taxa de desemprego é grande (causação inversa da suposta convencionalmente); b) não se pode concluir efetivamente que o aumento dos benefícios afeta a oferta de mão de obra, diminuindo o número e o tempo de procura por trabalho, pois "embora seja admissível a hipótese de que benefícios elevados diminuam a disposição de as empresas contratarem, de outro lado levam a uma maior participação na oferta de trabalho, dado que a participação é a condição necessária para a eventual obtenção desses benefícios” (Nickel, 1997, p. 67). De outro lado, Gregg e Manning, através de uma análise de regressão, para 16 países da OCDE, para o ano de 1990, não identificaram correlação positiva entre a taxa de desemprego e a duração dos benefícios, e obtiveram correlação negativa entre a taxa de desemprego e o valor dos benefícios (replacement rate) (conforme Gregg e Manning, 1997, pp. 406-7).

Em conclusão, se considerarmos o conjunto de instituições de mercado existentes nas principais economias capitalistas, e as possíveis formas de rigidez delas decorrentes podemos concluir que a relação entre esses fatores e as taxas de desemprego é muito variada e errática para explicar as diferentes taxas de desemprego, especialmente para justificar a alegação convencional de que as altas taxas de desemprego estão associadas a mercados de trabalho regulados e consequentemente à falta de flexibilidade salarial. Daí a necessidade de se considerar a hipótese de que a tendência à elevação do desemprego está ligada não só à tendência à queda da demanda agregada ao nível nacional, como também a uma tendência ao declínio do crescimento da demanda agregada, na maior parte das economias industrializadas.

\section{A MACROECONOMIA DO DESEMPREGO}

A ideia que orienta este tópico é a de relacionar o desemprego recente das economias europeias e americana com o desempenho da demanda global tanto ao nível nacional como internacional. O objetivo principal da análise é o de mostrar a dominância dos elementos macroeconômicos na determinação dos elevados níveis de desemprego na Europa em contraposição à interpretação microeconômica convencional; e não apenas mostrar que os fatores macroeconômicos também são importantes. Dessa maneira, a análise que segue vai procurar determinar até que ponto as oscilações na produção e no emprego, tem efetivamente uma natureza macroeconômica, tomando-se o macroeconômico no sentido keynesiano de movimentos na Demanda e Oferta Agregadas afetando globalmente o sistema. 


\section{A natureza macroeconômica dos ciclos de desemprego e seus determinantes}

A interpretação macroeconômica da recessão e do auge econômicos supõe que tais fenômenos estão ligados aos chamados choques agregados que podem ser positivos ou negativos. Exemplos dos últimos são as restrições de crédito, a elevação das taxas de juro decorrentes de decisões de política monetária, que afetam a capacidade de quase todas as firmas de investir em novos prédios e equipamentos; mudanças na tributação sobre os rendimentos e sobre os lucros das empresas, que afetam o lucro líquido e a capacidade de gasto; contrações nos gastos governamentais; ou ainda mudanças súbitas no preço dos insumos de uso generalizado, tais como a energia, que afetam os custos de produção; o oposto ocorrendo para os choques positivos. A hipótese macroeconômica pressupõe que tais choques independentemente de sua natureza, devem ter um efeito similar e simultâneo na maior parte dos setores ou das firmas da economia.

Tal efeito tem sido verificado empiricamente; isto é, tem ocorrido co-movimentos na produção e emprego na maioria dos setores econômicos ao longo das oscilações cíclicas das economias. Davis, Altinvanger e Schuh (1996), utilizando-se de informações para economia americana, mostram que tais co-movimentos existiram nos anos representativos das recessões de 1975 e 1982 e da expansão de 1975 e 1984 (pp. 85-6). De acordo com tais informações, todos os setores exibiram taxas de crescimento inferiores à média nas recessões e acima dela nas expansões, o mesmo acontecendo com o emprego. ${ }^{1}$

Outra observação empírica que apóia a explicação macroeconômica é a seguinte: os dados obtidos em nível setorial indicam pouca evidência de criação e destruição simultânea de emprego. Em outras palavras "a distribuição das taxas de crescimento dos setores industriais é altamente concentrada e não sugere uma economia sujeita a contínuas realocações de empregos em larga escala" (Davis et al, 1996, pp. 88-9). Se considerarmos a evolução das economias europeias e americanas, teremos uma confirmação mais estrita de tais hipóteses. Considerando os chamados gaps do produto efetivo em relação ao produto potencial ou de pleno emprego $^{2}$, vamos verificar que as duas áreas tiveram gaps negativos substanciais no início dos anos 80 . Nesse período, a política macroeconômica foi restritiva nas duas regiões. No entanto, com o controle da inflação a partir de 1985-86, pode-se notar grandes diferenças em sua evolução: se a União Europeia teve apenas 4 gaps positivos, no mesmo período os EUA tiveram apenas 3 anos de gap negativo. De 1992 em diante, quando os países europeus iniciaram o programa de Maastricht,

\footnotetext{
${ }^{1}$ Setores industriais com crescimento abaixo do crescimento médio representaram $85 \%$ do emprego em 1975 e $95 \%$ em 1982 (períodos de recessão); indústrias acima do crescimento médio de $95 \%$ em 1978 e 71 \% em 1984 (períodos de expansão)

${ }^{2} \mathrm{O}$ produto potencial das economias americana e europeia determinadas pela OECD é estimado com base em urna função de produção que considera: o estoque de capital, mudanças na oferta de trabalho, a produtividade dos fatores e taxa de salário correspondente ao NAIRU (non acelerating rate inflation)
} 
a União Europeia apresentou gaps anuais negativos de cerca de 2,25\%, consequência dos programas restritivos de ajuste então empreendidos.

Tais gaps de produção são determinados a partir de estimativas da OECD para o produto interno potencial dos países da UE (que coincide com o gap dos quatro maiores países desse grupo) e para o produto potencial americano. A relação entre esses gaps e as taxas de desemprego, tanto para a UE como para os EUA, pode ser identificada empiricamente através da análise de regressão realizada por Heylen et al. (1996, p. 29) apresentada abaixo. (Tabela 4)

Tabela 4: Análise de Regressão do desemprego na UE e nos EUA, 1980-95 Coeficientes estimados

\begin{tabular}{ccccccccc}
\hline & Constante & U (-1) & Gap & Gap (-2) & Tempo & R2 & SER & DW \\
\hline U.E. & 1,09 & 0,94 & 0,26 & 0,19 & $-0,049$ & 0,99 & 0,15 & 2,19 \\
& $(2,64)$ & $(16,5)$ & $(11,7)$ & $(5,14)$ & $(3,78)$ & - & - & - \\
\hline \multirow{2}{*}{ EUA } & 5,10 & 0,29 & $-0,52$ & - & $-0,047$ & 0,98 & 0,17 & 2,21 \\
& $(16,0)$ & $(6,79)$ & $(12,8)$ & - & $(4,17)$ & - & - & - \\
\hline
\end{tabular}

Nota: as equações foram estimadas em (3SLS), os valores de t estão dados entre parênteses, e a tendência temporal tem valores que vão de 1 para 1980 a 16 para 1995.

Fontes : OECD Economic Outlook (Dezembro, 1995) e Heylen et al. op. clt.

Tal análise evidencia que os gaps correntes e passados são determinantes altamente significativos do desemprego na UE. Tal regressão ainda mostra que a taxa de desemprego apresenta uma tendência temporal negativa (mantidas as demais variáveis constantes); isto é, o desemprego tenderia a cair ao longo do tempo, tanto para a UE como para os EUA. Isso significa que nos dois continentes ocorreram fatores não relacionados com a demanda, que tiveram um efeito positivo para a redução do desemprego: tais como a redução do preço do petróleo, uma eventual maior coordenação na barganha salarial entre patrões e emprega dos etc.

Finalmente outra informação importante dada na regressão acima é a estimação do coeficiente do lag da taxa de desemprego u(-1) sobre a taxa de desemprego presente. Para a UE é de 0,94, aproximado-se portanto da unidade, enquanto para a economia americana é de apenas 0,29 . Esses valores indicam que para a UE, embora o efeito negativo sobre o desemprego dos choques de demanda não sejam definitivos, pode demorar muitos períodos de tempo para serem reabsorvidos, ocorrendo o contrário para os EUA.

Isso indica uma tendência à persistência do desemprego nas economias europeias, que pode ser ilustrada pelos números da participação do desemprego de longo prazo (desempregados por mais de um ano), no desemprego total para Bélgica, Dinamarca, França, Alemanha, Irlanda, Itália, Holanda, Portugal e Espanha, que em seu valor médio foi de $46,1 \%$, contra a mesma relação que foi de $11,7 \%$ para os EUA (Fonte OECD Economic Outlook, vários números; Heylen et al., op. cit. ).

Tal constatação reforça a necessidade de se considerar o efeito dos fatores macroeconômicos na determinação da persistência do desemprego nas economias eu- 
ropeias, principalmente se considerarmos na regressão acima que os fatores clássicos da determinação do desemprego de longo prazo não apresentam uma correlação positiva com o crescimento da taxa de desemprego europeia. A hipótese a ser considerada é a de que os próprios choques de demanda, de curto prazo, determinam tendências na economia que se colocam como obstáculos a reabsorção do emprego.

\section{Choques de demanda e oferta e mecanismos de persistência na determinação do desemprego (EUA e UE)}

A existência de ciclos longos de desemprego pode ser interpretada, segundo alguns autores (Blanchard e Summers, 1986; Layard et ai., 1994; Snower, 1993), como formas de equ ilíbr io de desemprego. Sendo esse conceito de gra nd e impor tância para uma explicação adequada do desemprego europeu em relação ao ame ricano e para uma eventual definição de política de emprego, se discutirá a segui $r$ o modelo sugerido por Cha rles Bean (1997), através do qual se poderá identificar os determinantes cíclicos e de persistência (estrutural) no desemprego euro peu e americano.

Tal modelo será apresentado a partir dos gráficos a seguir.

Figura 1
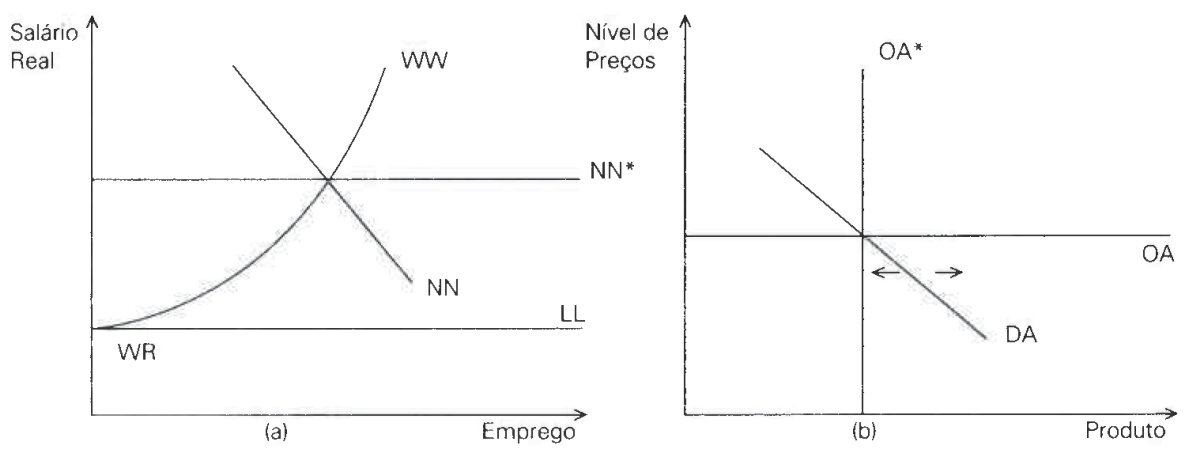

No gráfico a) da figura 1 estão representados: LL, como a oferta competitiva de mão-de-obra, sendo WR o salário de reserva. A curva WW indica uma pseudo função de oferta de trabalho, pressupondo que os salários são determinados, como consequência de um processo de barganha bilateral entre firmas e assalariados ou de um processo de determinação de salários de eficiência. Em ambos os casos, o prêmio sobre o salário de reserva tende a aumentar conforme tende aumentar o nível de emprego. NN é a função demanda de trabalho de médio prazo, representando as decisões ótimas de preço e emprego das firmas, sendo dados o salário nominal e o estoque de capital existente. O nível de emprego de equilíbrio é dado pela interseção de NN e WW. No longo prazo, o capital pode se ajustar levando a um deslocamento de NN para cima ou para baixo, conforme o capital se acumula ou desacumula. NN* pode ser interpretada como a demanda de longo prazo de 
mãode-obra, no caso da acumulação de capital ser endógena. A função será horizontal se se supuser rendimentos constantes de escala.

O gráfico 6) está associado com o gráfico a), expresso em termos de produção (renda) e nível de preços. DA é a curva de demanda agregada convencional, cuja inclinação negativa é explicada pelo efeito riqueza (real balance effect), taxas de juro real mais baixas e pelo efeito de ganhos de competitividade. OA* pode ser identificada como uma curva de oferta agregada pseudoclássica, na qual os salários nominais e os preços estão perfeitamente ajustados. Estabelece, assim, o produto de pleno emprego correspondente ao valor do emprego dado em $b$, pela interseção de WW e NN. Variações em DA determinam no longo prazo apenas variações no nível de preços. No curto prazo, no entanto, como se supõe que salários e/ou preços são rígidos em função de contratos ou de informação imperfeita, flutuações na demanda agregada, DA, levam a movimentos ao longo da curva de oferta agregada de curto prazo OA.

Com base em tal modelo, Charles Bean (1997) procura estabelecer a partir da análise de dados das economias da União Europeia e dos EUA o quanto do desemprego pode ser explicado por uma ou outra forma de perturbação, i. e., variações em $\mathrm{OA}^{*}$. ou DA. Para tanto, utiliza a técnica de vetor auto-regressivo (VAR) a partir de três variáveis: inflação, utilização de capacidade e o logaritmo da taxa de desemprego, determinando uma equação para cada uma dessa variáveis. Os dados são anuais e compreendem o período de 1964 a 1995 (projeções da OECD) para os dois últimos anos. Utiliza dois lags para cada variável, e uma constante; cada equação contém dummies para os períodos afetados pelos dois choques do petróleo, as quais apresentam o valor de uma unidade para os períodos de 1974 a 1976 e de 1989 a 1983.

Os resíduos estimados de um modelo de vetor auto-regressivo podem ser interpretados como uma combinação linear de perturbações econômicas relevantes. Assim, os resíduos da equação de desemprego deverão refletir tanto choques de oferta como choques de demanda, o valor dos quais pode ser identificado mediante certas suposições. Para tanto, considerando-se a equação da inflação e da utilização da capacidade se suporá em primeiro lugar que deslocamentos no mesmo período das funções WW e NN se refletem de modo imediato e integralmente na inflação, e, apenas após algum período de tempo, na utilização da capacidade; de outro lado, considera-se que deslocamentos na demanda agregada se refletem, imediatamente, apenas no nível de capacidade utilizada. O primeiro tipo de alteração pode ser identificado com um "choque de preços" de acordo com a interpretação macroeconômica convencional, provocado pela elevação do preço de um insumo ou pela elevação do salário de reserva. O segundo tipo de alteração corresponde a um choque de demanda agregada, no qual se supõem preços rígidos a curto prazo de tal modo que o efeito se refletirá imediatamente nas quantidades procuradas (ver para tal interpretação, Hall e Taylor, 1989, pp.124 ss.)

Dessa maneira, se do resíduo total da equação do desemprego se subtrair o resíduo correspondente às variações da capacidade instalada (decorrentes dos choques de demanda), teremos uma série temporal (linha pontilhadas da figura 2) que 
corresponde às taxas de desemprego das quais foram eliminados os choques de demanda. Essa linha está representada na figura referida juntamente com o valor efetivo da taxa de desemprego, que obviamente inclui tanto os choques de custo como os de demanda (linha cheia).

\section{Figura 2}
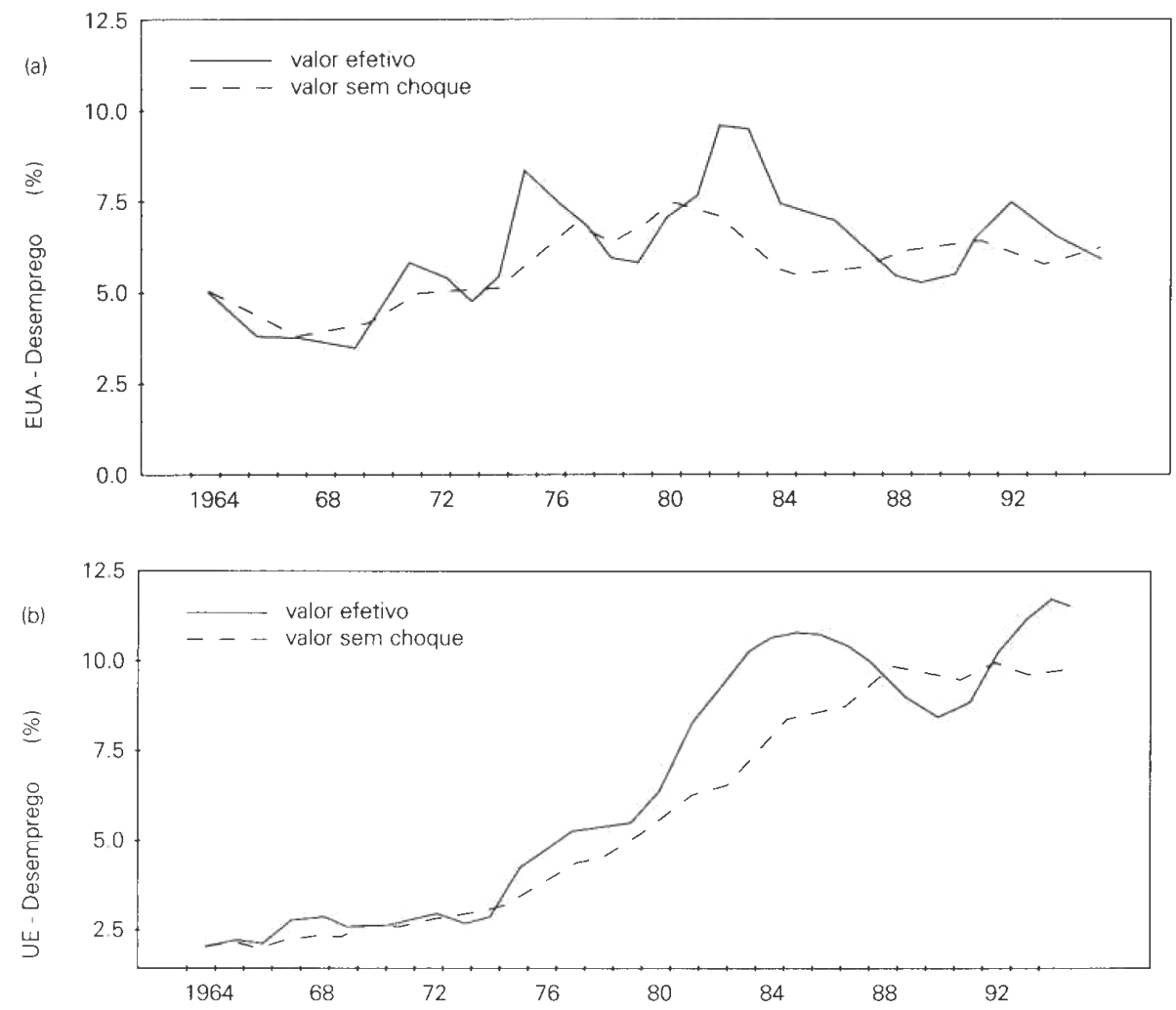

A simulação mostra que para o EUA os movimentos das taxas de desemprego se dão como flutuações cíclicas em torno de uma certa taxa de desemprego relativamente constante; ao passo que para a União Europeia temos uma taxa de desemprego obedecendo a uma tendência dada pelas variações na oferta, à qual se acresce um componente não desprezível de variações decorrentes da demanda (a distância entre a linha cheia e a pontilhada).

O comportamento da taxa de desemprego para a UE mostra uma característica importante em relação à dos EUA, i.e., a sua persistência quando comparada com as oscilações em torno de uma taxa natural estável apresentada para a economia amencana. 


\section{Mecanismos de persistência: o lado da demanda}

As constatações acima têm levado vários autores a procurar a explicação da permanência do desemprego em mecanismos através dos quais deslocamentos na demanda agregada têm um efeito de longo prazo na taxa de desemprego, também identificado como efeito de histerese; ou seja as taxas atuais do desemprego estão relacionadas positivamente com o desemprego passado.

Em relação aos choques da demanda, identificam-se quatro mecanismos de persistência, dois afetando a oferta do mercado de trabalho (a função WW) e dois afetando a demanda de trabalho (função NN). O primeiro é identificado pelo chamado "insider outsider effect", tal como formulado por Lindbeck e Snower (1998) e Blanchard e Summers (1986). Choques de demanda inicialmente podem levar à formação de insiders, isto é, aqueles assalariados que não perdem seus postos, e que eventualmente podem formar grupos de resistência, com poder de barganha, para manter seus salários acima dos salários de equilíbrio. Tal poder ainda pode ser reforçado pela ação sindical, e por custos inevitáveis de contratação e dispensa. Tais grupos têm condições de resistir às pressões que os outsiders impõem para obter uma vaga. "Assim quando as condições de mercado são boas os salários (dos insiders) tendem a se ajustar para cima, na medida em que os insiders deixam de temer a perda de emprego. Isto dificulta aos outsiders se aproveitarem da retomada do ciclo para cima a fim de obter trabalho. Assim os desempregados que foram excluídos do mercado praticamente não participam no processo de preenchimento das vagas disponíveis" (Cohen, 1995, p. 50).

O segundo efeito da existência de altas taxas de desemprego tem a ver com os próprios desempregados. Uma situação de desemprego tende a reduzir a capacidade de trabalho dos desempregados ou impedir que obtenham novas habilidades e/ ou enfraquecer seus hábitos de trabalho. Essa situação faz com que os recém-desempregados tenham melhores condições de obter emprego que os desempregados há mais tempo.

De outro lado (terceiro efeito), a percepção por parte das empresas de uma queda da qualificação da mão-de-obra, em função de um choque adverso de demanda, leva as empresas a abrirem menos vagas, perpetuando o problema dos desempregados há mais tempo. A persistência do desemprego faz também com que os desempregados considerem um exercício fútil continuar procurando trabalho, levando-os a abandonar a procura de emprego.

Quanto à demanda de trabalho, dada a existência de custos de contratação e dispensa, o primeiro mecanismo está relacionado com o fato de que a empresa apenas contratará mais se tiver certeza de que a demanda agregada se manterá por razoável período de tempo. Finalmente, choques de demanda podem afetar o estoque de capital, reduzindo-o. Um choque adverso da demanda ao causar desemprego pode criar ociosidade de capital levando a um processo de desacumulação.

\section{Os efeitos da política econômica sobre a oferta agregada}

Além dos mecanismos de persistência determinados por variações na demanda agregada, deve-se considerar de que maneira a política macroeconômica pode afetar 
a oferta agregada $\left(\mathrm{OA}^{*}\right)$.Desses mecanismos, o que tem recebido maior atenção é o efeito dos tributos, ao determinarem a cunha fiscal entre o custo do trabalho para a firma e o poder aquisitivo do salário após a tributação. Em termos do gráfico a) da figura 1, dado que NN é a demanda de mão-de-obra em função de um dado estoque de capital e de um dado salário nominal, uma elevação da tributação direta sobre o consumo elevará o custo do trabalho para a firma, para um dado poder aquisitivo de salário, fazendo com que NN se desloque para baixo, reduzindo o volume de emprego. O problema com tal hipótese é o de como será afetado o salário de reserva. Este na verdade é determinado não apenas pelo volume dos benefícios ao desempregado, mas também pelo nível de poupança do trabalhador, pelo acesso ao crédito e pelo apoio de outros membros da família. Ora, uma elevação da tributação deverá reduzir também o valor do salário de reserva, fazendo com que WW se desloque para a direita, compensando eventualmente a queda de NN.

Outra hipótese relevante relativa ao lado da oferta da economia, isto é, a OA*, é a de que a determinação do emprego é consequência das variações na taxa de juro. Uma elevação da taxa de juro real vai elevar o custo do capital causando uma desacumulação de capital e uma redução da demanda de mão-de-obra. No gráfico a) da figura $1, \mathrm{NN}^{*}$ pode deslocar-se para baixo, em consequência de NN deslocarse para a esquerda ao longo do tempo. Phelps (1994), em Structural Slumps, detalhou uma série de canais através dos quais uma elevação da taxa de juro real teria condições de deslocar para a esquerda as funções WW e NN, em ambos os casos reduzindo o emprego. Consideremos especialmente os determinantes possíveis do deslocamento da demanda de trabalho $(\mathrm{NN})$. Segundo Phelps, a variável mais importante seria o preço descontado dos rendimentos gerados por cada um dos ativos das firmas, ao longo do tempo. Para construir um modelo de equilíbrio geral, ele considera três ativos não-financeiros; estoque de mão-de-obra (capital humano); estoque de clientes da firma; e capital físico. "A característica comum desses estoques é que todos estão relacionados com o estoque de mão-de-obra, i.e., eles medem o valor presente do estoque de mão-de-obra empregado em uma firma representativa. Assim, uma mudança em q (o valor presente dos rendimentos futuros de tais ativos), para qualquer ativo, afetará o valor presente descontado do estoque corrente de empregados da firma, e assim o nível de equilíbrio de longo prazo (ceteris paribus) que a firma está disposta a manter" (Van Hess e Garretsen, 1997, p. 192). Assim, uma elevação da taxa de juro real poderá, por exemplo, reduzir a demanda de capital físico e deslocando NN para a esquerda, a médio prazo; estabelecendo um novo nível de emprego, equilíbrio de longo prazo, com $\mathrm{NN}^{*}$ deslocando-se para baixo.

Daí Phelps explicar o desemprego europeu "pelo permanente crescimento da taxa real de juro internacional que eleva imediata e permanentemente a taxa natural de desemprego de qualquer país que esteja integrado com o mercado de capitais mundial. A teoria é que esse parâmetro externo reduz a curva de demanda de trabalho $(\mathrm{NN})$ em relação à curva de oferta, resultando numa redução na taxa de emprego. "A elevação da taxa real de juro internacional opera através do canal da taxa interna de juro, a qual se eleva naturalmente; o efeito contracionário dos 
custos mais elevados da taxa de juro no preço real de demanda de trabalho é um velho tema da teoria do capital. Esta conclusão, portanto, não deve ser surpreendente" (Phelps, 1995, p. 229).

\section{POLÍTICA ECONÔMICA E DESEMPREGO}

Se considerarmos os resultados apresentados na figura 2, vamos perceber dois fatos interessantes: o comportamento do desemprego nos EUA se ajusta à representação convencional dos livros-textos de macroeconomia, isto é, o movimento do desemprego constitui-se em flutuações cíclicas em torno de uma taxa de desemprego razoavelmente estável; enquanto, para a UE, temos uma situação em que a chamada taxa de desemprego não-cíclico se eleva; juntamente com ela se eleva também a taxa cíclica, porém sem oscilar em torno daquela. Uma das interpretações possíveis desse comportamento é de que, nos EUA, há mecanismos de compensação que fazem com que quando o desemprego esteja muito abaixo de uma determinada taxa, a política econômica, especialmente a política monetária será utilizada para fazer com que o desemprego caia, e vice-versa. Uma situação semelhante não se encontra no caso da UE; mesmo supondo-se que o desemprego cíclico não seja o determinante maior do desemprego, nota-se que não ocorrem os mencionados mecanismos de compensação através da política econômica ativa. A hipótese a ser considerada a partir desses fatos é a seguinte: na medida em que os choques de demanda na economia europeia não são neutralizados por uma política monetária mais flexível há uma tendência clara a se acumularem os efeitos de persistência ("histerese") discutidos anteriormente.

Essas observações colocam as seguintes questões: por que os EUA conseguiram aplicar uma política de estabilização em relação ao emprego? Por que razões as mesmas políticas não teriam sido aplicadas em grande parte dos países da UE? Considerando-se os anos 80, vamos identificar na economia americana a aplicação de políticas fiscais expansionárias que levaram a déficitis orçamentários em torno de 3,5\% do PIB, determinados pelo aumento dos gastos da defesa, simultaneamente com um corte generalizado da tributação incidente sobre os grupos de renda mais alta, estimulando assim a demanda agregada. No mesmo período, as economias europeias tiveram déficits que decorreram basicamente da redução da receita tributária e do aumento dos gastos de "welfare", precipitados por condições recessivas. Além disso, os EUA praticaram políticas monetárias independente s expansionistas e anticíclicas, possíveis de serem realizadas pelas condições específicas da economia americana, que serão mencionadas adiante, tornando possível a redução das taxas de juro, toda vez que a economia mostrasse sinais de enfraquecimento.

Assim, nos EUA, na recessão de 1981-2, quando o desemprego aumentou além do ponto considerado adequado, reduziu-se a taxa dos títulos públicos de $16,4 \%$ em 1981 para 9,1\% em 1983. Na recessão mais recente, a taxa caiu de 5,5\% em 1991 para 3\% em 1993. O mesmo não ocorreu na Europa, que, em função do receio da volta da inflação dos anos 70 e pela autoridade exercida pelo Bundesbank, 
foi muito menos sensível à necessidade de uma redução da taxa de juro quando as condições do emprego começaram a deteriorar-se. O que ocorreu com a taxa de juro real de curto prazo nos EUA e nos E-4 está ilustrado na figura 3.

Figura 3: Evolução da Taxa de Juro Real para a UE e os EUA, 1978-95

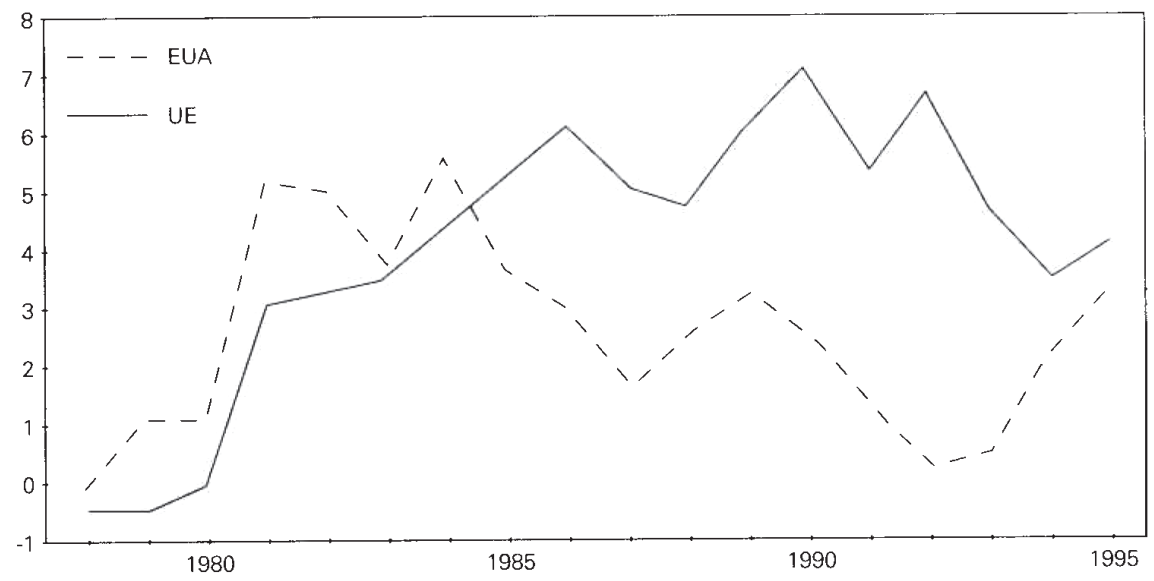

Fonte: OECD Economic Outlook (Dezembro, 1995) e Heylen et al., op.cit.

Tanto os EUA como a União Europeia optaram por contrações monetárias severas no início dos anos 80 , com a taxa de juro se elevando grandemente. No entanto, na segunda metade dos anos 80 , enquanto a taxa americana tende a baixar rapidamente chegando quase a zero (1992), a taxa de juro europeia se manteve extremamente alta.

Figura 4: Evolução do Défict Orçamentário Est rutural (EUA e UE, 1978-96)

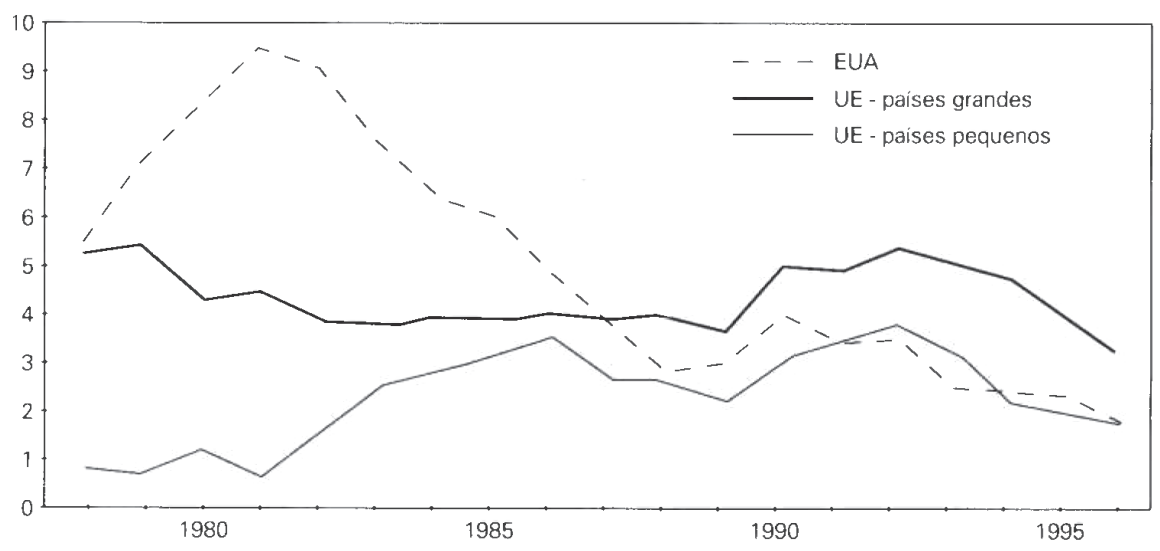

Fonte: OECD Economic Outlook (Dezembro. 1995) e Heylen et al. op.cit. 
A figura 4 descreve a evolução do déficit orçamentário estrutural (ajustado para o ciclo), no qual mudanças discricionárias do orçamento são interpretadas como impulsos positivos ou negativos para a economia. $\mathrm{Na} \mathrm{UE}$, tais mudanças reforçam o efeito da política monetária ao aumentar a contração no período 198083 (redução do déficit). Após uma elevação do déficit nos anos 1990-92 (reunificação alemã), a política fiscal retorna para um padrão deflacionário (Acordo Maastricht). Algo semelhante ocorre com os países europeus menores (Bélgica, Dinamarca, Irlanda e Países Baixos). No caso da economia americana o quadro é diferente. O padrão da política fiscal foi expansionário na maior parte do período em consideração. O déficit estrutural permenece alto no período 1980-86, neutralizando o efeito contrario da política monetária do início dos anos 80; como também em 1990-92, reforçando os efeitos expansionários da política monetária no período. De qualquer maneira, fica claro o caráter compensatório do déficit nos EUA, o que não ocorre na UE.

De maneira mais específica, duas foram as razões do comportamento europeu comparado com o americano. As economias europeias são muito mais abertas que a economia americana. Considerando-se a medida de 0 para uma economia absolutamente fechada, isto é, que não realiza nenhuma importação e 1 para uma economia absolutamente aberta, na qual todo gasto doméstico constitui-se de importações, temos um grau de abertura de 0,10 para os EUA e 0,31 para a economia europeia. Isso significa que a economia europeia fica muito sujeita à inflação importada decorrente de uma depreciação cambial, daí a alternativa de se buscar o equilíbrio externo mediante a elevação da taxa de juro. Essa opção foi institucionalizada nos anos 80, através do Mecanismo Cambial Europeu (ERM), que forçava os países à manutenção das taxas de juro em patamar elevado, para se adequarem assim a limites determinados.

Tais condições não são as únicas para explicar por que, a partir de uma determinada data, elas passaram a determinar da maneira acima as suas políticas econômicas. As novas condições do sistema financeiro internacional, que passam a se delinear a partir do fim do sistema de Bretton Woods, estabeleceram as bases de um sistema financeiro altamente desregulado em nome de uma maior eficiência. Assim, em 1974, os EUA anunciam a retirada de todo mecanismo de controle dos fluxos de capital. Essa desregulamentação determinada, em parte, pelo sistema de cambio flexível, tem como principal contrapartida o surgimento de mecanismos de hedge diante dos custos da flutuação impostos ao setor privado. Isso demandou a criação de novos instrumentos financeiros, que por sua vez requeriam a eliminação de regulações que eventualmente limitassem a constituição desses instrumentos. Nesse contexto, controles de câmbio foram eliminados. "Restrições domésticas ao acesso aos mercados para instituições financeiras deixaram de existir. Controles quantitativos ao crescimento dos créditos desapareceram, e a política monetária passou a ser conduzida, predominantemente, através da administração das taxas de juro de curto prazo. Um mercado global de instrumentos monetários estava sendo criado" (Eatwell, 1996, p. 11).

O grau de instabilidade desse mercado ficou patente quando do ataque à libra 
em setembro de 1992. O governo inglês, apesar de ter uma disponibilidade de 15 bilhões de dólares para defender a paridade da libra, não conseguiu se contrapor à venda dessa moeda realizada por apenas um participante do mercado de divisas. Nesse contexto, o conceito de "credibilidade no mercado" se tornou a pedra angular da política econômica especialmente nos anos 90. Uma perda radical de credibilidade poderá levar facilmente a uma crise financeira, mas a determinação do que seja a "credibilidade" de uma economia ou de um governo dependerá basicamente de decisões que se tomam em um mercado especulativo. Como Keynes já havia mostrado, com clareza, a credibilidade em tais situações não se forma em função de uma análise objetiva dos fundamentos da realidade econômica, mas é antes o resultado da aceitação "slogans" tais como "déficits fiscais elevados levam a taxas de juro mais altas; uma oferta monetária elevada resulta em altas taxas inflacionárias, o gasto público é ruim, o gasto privado é bom - mesmo quando tais slogans são persistentemente refutados pelos fatos" (Eatwell, 1996, p. 13)

As demandas de credibilidade nos anos 80 e 90 em função dos interesses constituídos pela "haute finance" impuseram de forma generalizada estratégias macroeconômicas deflacionárias ao G7. As condições dos mercados financeiros desregulados encorajaram políticas que reforçaram (e reforçam) uma elevada instabilidade financeira. Isso se refletiu sobre as taxas reais de juro, cuja elevação reduziu o investimento interno e, em consequência, reduziu o crescimento do comércio internacional.

Assim, de acordo com Thomas Palley (1998, pp. 345 ss.), se as considerações sobre a taxa de câmbio limitaram a possibilidade de realização de políticas monetárias autônomas, as considerações sobre o balanço de pagamento limitaram esses países europeus em termos de realização de políticas fiscais de pleno emprego. Sem um mínimo de coordenação, dada a grande abertura desses países entre eles, qualquer esforço de se aumentar o gastos públicos, realizado por um país isoladamente, terá como efeito o aumento de suas importações sem a contrapartida do aumento de suas exportações; beneficiando as exportações daqueles países que não aumentaram tais gastos. Tal fato obviamente terá como consequência um desequilíbrio externo que deverá ser compensado por uma elevação da taxa de juro.

Em uma situação como a europeia, tal tendência é dominante: há incentivos para a elevação da taxa de juro sobre o valor médio da taxa internacional, para reduzir a possibilidade de inflação e a fuga de capitais. Quando todos os países procedem dessa maneira, isso resulta em taxas de juro elevadas em todos eles. Simultaneamente, haverá uma tendência a reduzir-se o gasto público e o déficit. Se um país, de outro lado, praticar uma política monetária expansionária, estará diante da possibilidade de uma crise cambial, com implicações inflacionárias, pois taxas reduzidas de juro nessas condições com perspectivas inflacionária levarão a uma fuga de capital. A demanda por importações aumentará, elevando o déficit externo. De outro lado, se um país praticar, isoladamente, uma expansão fiscal, a perspectiva de inflação elevada determinará uma fuga de capital simultaneamente com o aumento das importações. Em ambos os casos, o resultado será desequilíbrio interno e externo e a necessidade de reversão dessas políticas. 


\section{CONCLUSÃO}

Através da análise das tendências macroeconômicas e das políticas macroeconômicas às quais os países europeus foram condicionados, podemos ter uma explicação alternativa do comportamento do desemprego nessas economias, em relação à economia americana. Tal análise serve também para reforçar a desconfiança em relação à hipótese de que a origem das altas taxas de desemprego observadas naqueles países possam ser explicadas por considerações microeconômicas relativas a existência de grandes inflexibilidades nos mercados de trabalho. Obviamente, esses fatos apontam para a necessidade de uma política de emprego que transcenda as simples medidas de desregulamentação desses mercados.

\section{REFERÊNCIAS}

BEAN, Ch. (1997) “The Role of Demand Policies in Reducing Unemployment”, in SNOWER e DEHESA, eds. Unemployment Policy, Cambridge, Cambridge University Press.

BENTOULA, S. e BERTOLA, G. (1990) "Firing Cost and Labour Demand: How Bad is Eurosclerosis" Review of Economic Studies, vol. 57, pp. 381-402.

BENTOLILA, S. e DOLADO, J. J., (1994) “ Labour Flexibility and Wages: Lessons From Spain “, Economic Policy, 18, pp. 53-100.

BLANCHARD, O. e SUMMERS, L. H. (1986) “ Hysteresis and European Unemployment Problem”, in S. Fischer, ed. Macroeconomics Annual, Cambridge, Ma., MIT Press, pp. 15-77.

BLONDAL, G. e PEARSON, M . (1995) “Unemployment and other unemployment Benefits”, Oxford Review of Economic Policy, vol.11, 11 ${ }^{\circ}$. 1, pp. 136-69.

BUCHELLE, R. e CHRISTIANSEN, J. (1998) "Do Employment and Income Security Cause Unemployment? A Comparative Study of the US and the E-4", Cambridge Journal of Economics, vol. 22, n” 1 , pp. 11 7-36.

COHEN, D. (1995) The Misfortunes of Prosperity, Cambridge, MA, The MIT Press.

DAVIS, S. J. et al., (1996) Job Creation and Destruction, The MIT Press Cambridge, MA, London, England.

DRÉZ E, J. (1996) “Employment in Europe”, in The Social Challenge of Creation of Jobs, em GUAL, J. (1996) (ed.), op. cit.

EATWELL, J. (1996) “ Unemployment on a World Scale”, in EATWEL (ed.), Global Unemployment: Loss of Jobs in the 90s, Armonk, New York, M. E. Sharpe.

GREGG, P. e MANNING, A. (1997) “Labour Market Regulation and Unemployment”, in SNOWER e DEHESA (eds.) Unemployment Policy, Cambridge University Press.

GUAL, J. (ed.) (1996) The Social Challange of Job Creation Combating Unemployment in Europe, Chaltenhem, UK, Edward Elgar.

HALL, R.E. e TAYLO R, J. B. (1989) Macroeconomia, Rio de Janeiro , Ed. Campus.

HEYLEN, F., GOUBERT L., OMEI, E. (1996) "Unemployment in Europe: A Problem of Relative or Aggregate Demand Shocks”, in International Labour Review, vol. 135, nº 1 , pp. 17-36.

HILL, C., GRIFFITHI S, W., e JUDGE, G. (1999) Econometria, São Paulo, Ed. Saraiva.

LAYARD et. al. (1994) The Unemployment Crisis. Oxford University Press.

LINDBECK, A. (1993) Unemployment and Macroecomomics. Cambridge, MA, The MIT Press.

LINDBECK, A. e SNOWER, D. J. (1988) The Insider Outsider Theory of Unemployment, Cambridge MA, The MIT Press.

MALINVAUD, E. (1996) “ Edmund Phelps, Theory of Structural Slump and its Policy Implication”, in SNOWER e DEHESA, op. cit. 
NAVARRO, V. (1998) “Eurosclerosis versus V.S. Dynamism”, Challenge, vol. 41 (4), pp. 66-75 .

NICKEL, S. (1997) “Unemployment and Labour Market Rigidities”, Journal of Economic Perspectives, vol. 11, pp. 55-74.

OECD - Job Study, Investiment Productivity and Employment, Paris, vários números.

OECD Economic Outlook, vários números.

OECD Employment Outlook, vários números.

PALLEY, T. (1998) “ Restoring Prosperity: Why The U.S. model is not the answer for the US or Europe” Journal of Post Keynesian Economics, vol. 17, $\mathrm{n}^{\circ}$ 2, pp. 337-53.

PELAGIDIS, T. (1998) "European Unemployment: Myths and Realities”, Challenge, vol. 41(4), pp. 7689.

PHELPS, E. (1995) “The Structuralist Theory of Unemployment”, American Economic Review, vol. 85(2), pp. 227-31.

PHELPS, E. (1994) Structural Slump: The modern Equilibrium Theory of Unemployment, Interest and Assets, Cambridge, Harvard University Press.

SNOWER, D. J. e DEHESA, G. (eds.) (1997) Uneployment: Government Options for the Labour Market, Cambridge, Cambridge University Press.

THE ECONOMIST, abril de 1998, EMU Survey, p. 7.

VAN HESS, H. e GARRETSEN, G. (1996) “Endogeneizing the Natural Rate of Unemployment", PHELPS Structural Slumps and the Post Walrasian Framework, in COLLENDER (ed.), op. cit. 